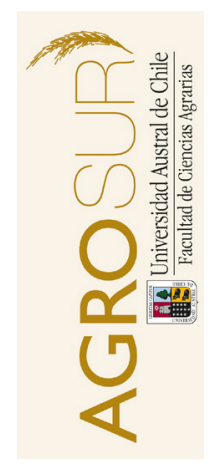

\title{
Efecto de la frecuencia de defoliación y de la fertilización nitrogenada sobre la producción y calidad nutritiva de una pradera de Lolium perenne $\mathrm{L}$.
}

\author{
Effect of defoliation frequency and nitrogen fertilization on herbage \\ production and nutritive quality of a Lolium perenne L. sward
}

\author{
Werner, $\mathbf{P}^{a}$, Balocchi, $\mathbf{0}^{b *}$, Loaiza, $\mathbf{P}^{c}$ \\ ${ }^{a}$ Escuela de Graduados, Facultad de Ciencias Agrarias, Universidad Austral de Chile, Casilla 567, Valdivia \\ ${ }^{b}$ Instituto de Producción Animal, Facultad de Ciencias Agrarias, Universidad Austral de Chile, Casilla 567, Valdivia \\ ${ }^{c}$ Dairy Link, Bilbao 1860, Osorno, Chile.
}

\begin{tabular}{l} 
A R T I C L E I N F O \\
\hline Article history: \\
Received 20.11.2018 \\
Accepted 21.12.2018 \\
\hline Keywords: \\
Dry matter yield \\
Nutrient content \\
Tiller density \\
Leaf area \\
Crude protein \\
\hline Original Research Article, \\
Animal Science \\
\hline *Corresponding author: \\
Oscar Balocchi \\
E-mail address: \\
obalocch@uach.cl
\end{tabular}

\begin{abstract}
A B S T R A C T
A study was conducted in Valdivia, Chile, to evaluate changes in dry matter production, nutritional quality, tiller density, leaf area and light interception in a pasture of Lolium perenne L., submitted to different levels of nitrogen $(\mathrm{N})$ fertilization and defoliation frequencies. The $\mathrm{N}$ levels used were $0,75,150,300$ and $450 \mathrm{~kg} \mathrm{~N} \mathrm{ha}^{-1}$ year $^{-1}$, applied monthly based on the rate of pasture growth. The defoliation frequency was based on the number of leaves per tiller and corresponded to 2 and 3 fully expanded leaves per tiller. A complete randomized block design with a factorial arrangement of five levels of $\mathrm{N}$ and two defoliation frequencies. Nitrogen fertilization had an effect on herbage mass, nutritional quality, tiller density, leaf area and light interception. Biomass production increased as it did the level of $\mathrm{N}$ fertilization. For the nutritional parameters, the higher levels on $\mathrm{N}$ fertilization increased the dry matter content, the crude protein, the metabolizable energy, the neutral detergent insoluble nitrogen and the soluble protein. The neutral detergent fiber, acid detergent fiber and soluble carbohydrates decreased. Fertilization also favored tiller density, leaf area per tiller and the light intercepted. The frequency of defoliation had no effect on herbage mass, but with higher frequency of defoliation crude protein, the neutral detergent insoluble nitrogen and soluble protein increased, while neutral detergent fiber and acid detergent fiber were higher with a lower frequency of defoliation.
\end{abstract}

\section{RESUMEN}

En Valdivia (Chile), se llevó a cabo un estudio para evaluar la producción de fitomasa, calidad nutritiva, densidad de macollos, área foliar e intercepción de luz en una pradera de Lolium perenne L., sometida a distintos niveles de fertilización nitrogenada y dos frecuencias de defoliación. Los niveles de $\mathrm{N}$ utilizados fueron $0,75,150,300$ y $450 \mathrm{~kg} \mathrm{~N} \mathrm{ha}^{-1}$ año-1 parcializados mensualmente de acuerdo a la tasa de crecimiento de la pradera. La frecuencia de defoliación se basó en el número de hojas por macollo y correspondió a 2 y 3 hojas completamente expandidas por macollo. Se usó un diseño experimental de bloques completos al azar con arreglo factorial de cinco niveles de $\mathrm{N}$ y dos frecuencias de defoliación. La fertilización $\mathrm{N}$ tuvo efectos sobre la fitomasa producida, calidad nutritiva y densidad de macollos. La producción de fitomasa aumentó con el nivel de fertilización nitrogenada. El incremento en la fertilización N aumentó el contenido de proteína cruda (PC), energía metabolizable, nitrógeno insoluble en la fibra detergente neutro y proteína soluble, y disminuyó la fibra detergente neutro, fibra detergente ácida y carbohidratos solubles. La fertilización $\mathrm{N}$ incrementó la densidad de macollos. La frecuencia de defoliación no tuvo efectos sobre el rendimiento de fitomasa, pero sí sobre algunos parámetros nutritivos. Los valores de PC, nitrógeno insoluble en la fibra detergente neutro y proteína soluble fueron más altos con la mayor frecuencia de defoliación, en tanto, los de fibra detergente neutro y fibra detergente ácido fueron más altos con la menor frecuencia de defoliación.

Palabras clave: producción de fitomasa, contenido de nutrientes, densidad de macollos, área foliar, proteína cruda.

\section{INTRODUCCIÓN}

Lolium perenne L. es la especie más utilizada en la siembra de praderas permanentes del sur de Chile alcanzando un $80 \%$ de las especies perennes sembradas (Andwandter et al., 2008). Esto se debe principalmen- te a su potencial productivo y a su buen valor nutritivo en comparación a otras gramíneas usadas en praderas permanentes de clima templado (Waite et al., 1964). En las condiciones agroclimáticas del sur de Chile las praderas sembradas con L. perenne obtienen rendimientos entre 11 y 15 ton MS ha-1. Estos rendimientos son posi- 
bles en gran medida a la utilización de fertilización nitrogenada (Teuber y Elizalde, 1999), lo que a su vez influye en la cantidad y concentración de PC de la pradera y consecuentemente en la dieta animal (Correa y Cuellar, 2004). Este alto nivel de PC en las praderas, puede constituirse en un problema y es una de las principales causas de porque en el sur de Chile se tienen niveles alrededor de $36 \mathrm{mg}$ de urea por $100 \mathrm{~mL}^{-1}$ de leche (Wittwer et al., 1993), mientras que los valores adecuados

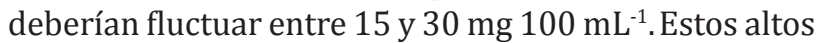
niveles de urea afectan la cantidad de leche producida y la salud animal. Una posibilidad de manejar indirectamente este problema es a través de la fertilización nitrogenada de la pradera (Pedraza et al., 2006).

Lolium perenne es una especie que posee tres hojas vivas por macollo en forma simultánea y al comenzar a nacer la cuarta hoja la primera comienza a morir, perdiendo de esta forma calidad, por eso se recomienda defoliarla cuando se encuentra entre 2 y 3 hojas (Pembleton et al., 2017). Con menos de dos hojas L. perenne presenta menor rendimiento y el contenido de PC es mayor (Donaghy y Fulkerson, 1999).

La frecuencia de defoliación afecta la supervivencia y crecimiento de la pradera (Fulkerson y Lowe, 2002), por eso es importante definirla para cada especie, dependiendo principalmente de la velocidad de recuperación de la pradera, que está dada por el número de hojas, la altura de la pradera, número de días entre pastoreo y fitomasa acumulada (Barker et al., 1985; Van Loo, 1992). Los tres últimos criterios varían con las estaciones del año, no así el primero. La frecuencia de defoliación influye en la tasa de macollamiento de la pradera, sobre la cual también influye la cantidad de radiación interceptada, postulándose que con defoliaciones más frecuentes (en 2 hojas) y debido a que ingresa más radiación a la base de las plantas, se incentiva la generación de nuevos macollos (Auda et al., 1966; Grant et al., 1981) y paralelamente aumenta la concentración de PC de la pradera (Michell y Fulkerson, 1987; Reyes et al., 2000). Otro factor que influye en la tasa de macollamiento es la estación del año, en verano e invierno esta es el doble que en primavera y otoño (Velasco et al., 2007).

De los nutrientes, el $\mathrm{N}$ es el que más influye en el crecimiento de la pradera (Bochi et al., 2009), además se ha visto que aumenta la tasa de aparición de hojas con mayor fertilización nitrogenada (Wilman y Pearse, 1984; Davies, 1971). Es así que con mayor fertilización la pradera presenta mayor tolerancia al ser defoliada. Sin embargo, se ha visto que en las hojas muertas de plantas fertilizadas con más $\mathrm{N}$ también hay una mayor concentración de N, lo que significa que son menos eficientes en el uso del $\mathrm{N}$ aplicado (Gastal et al., 2010).

La pradera experimenta un aumento lineal de la producción de fitomasa junto con el aumento de la fertilización nitrogenada (Whitehead, 1995), mejorando también su tolerancia a la defoliación (Gastal et al., 2010). Como consecuencia de la fertilización $\mathrm{N}$ también aumenta la concentración de PC, incrementándose el contenido de proteína verdadera y de $\mathrm{N}$ no proteico (Pacheco y Waghorn, 2008). Si hay un exceso de PC se pueden llegar a alterar las características organolépticas de la leche y sus subproductos, producir daños a la salud del animal y contaminación al medio ambiente (Keim y Anrique, 2011).

El objetivo de este estudio fue evaluar el efecto de la frecuencia de defoliación y nivel de fertilización nitrogenada sobre el rendimiento de fitomasa, calidad nutritiva y densidad de macollos de una pradera de L. perenne, durante la temporada primavera - verano.

\section{MATERIAL Y METODO}

El estudio se realizó entre septiembre de 2011 y febrero de 2012 en la Estación Experimental Santa Rosa de la Universidad Austral de Chile, Valdivia, Chile, ubicada a $39^{\circ} 46^{\prime} \mathrm{S}$ y $73^{\circ} 13^{\prime} 0$, a una elevación de $16 \mathrm{~m} \mathrm{~s} . \mathrm{n} . \mathrm{m}$.

El clima se clasifica como templado lluvioso con influencia mediterránea y se caracteriza por alta humedad relativa, bajas temperaturas y alta pluviometría que alcanza $2500 \mathrm{~mm}$ anuales distribuidos a través del año y concentrados en invierno. La temperatura promedio anual es de $11^{\circ} \mathrm{C}$ (Dirección Meteorológica de Chile, 2001). En la Figura 1 se observan las temperaturas mínimas, medias, máximas y las precipitaciones para el periodo de experimentación.

El suelo pertenece a la seria Valdivia y se caracteriza por ser proveniente de cenizas volcánicas, con altos contenidos de materia orgánica, pero baja tasa de mineralización lo que lleva a niveles de $\mathrm{N}$ mineral medios a bajos. La topografía del sector está dominada por pendientes entre $2-8 \%$ y sectores con ondulaciones leves de 2 al 5\% (IREN-UACh, 1978). El sitio del experimento presentó una topografía con leve pendiente de orientación Este.

\section{Establecimiento del ensayo}

En el Cuadro 1 se muestran los resultados del análisis de suelo realizado a $20 \mathrm{~cm}$ de profundidad en el mes de Septiembre. Posteriormente, durante Octubre se realizó una fertilización que incluyó $1000 \mathrm{~kg} \mathrm{ha}^{-1}$ de Carbonato de Calcio, $145 \mathrm{~kg} \mathrm{ha}^{-1}$ de Superfosfato Triple $\left(66,7 \mathrm{~kg} \mathrm{P}_{2} \mathrm{O}_{5}\right), 200 \mathrm{~kg} \mathrm{ha}^{-1}$ de Muriato de Potasio (120 $\mathrm{kg} \mathrm{K}_{2}$ O) y $200 \mathrm{~kg} \mathrm{ha}^{-1}$ de Fertiyeso (36 kg S).

Se utilizó una pradera establecida con Lolium perenne cv. Arrow, de cuatro años. La pradera había sido utilizada para estudios previos en que fue defoliada con el mismo régimen adoptado en este estudio. 


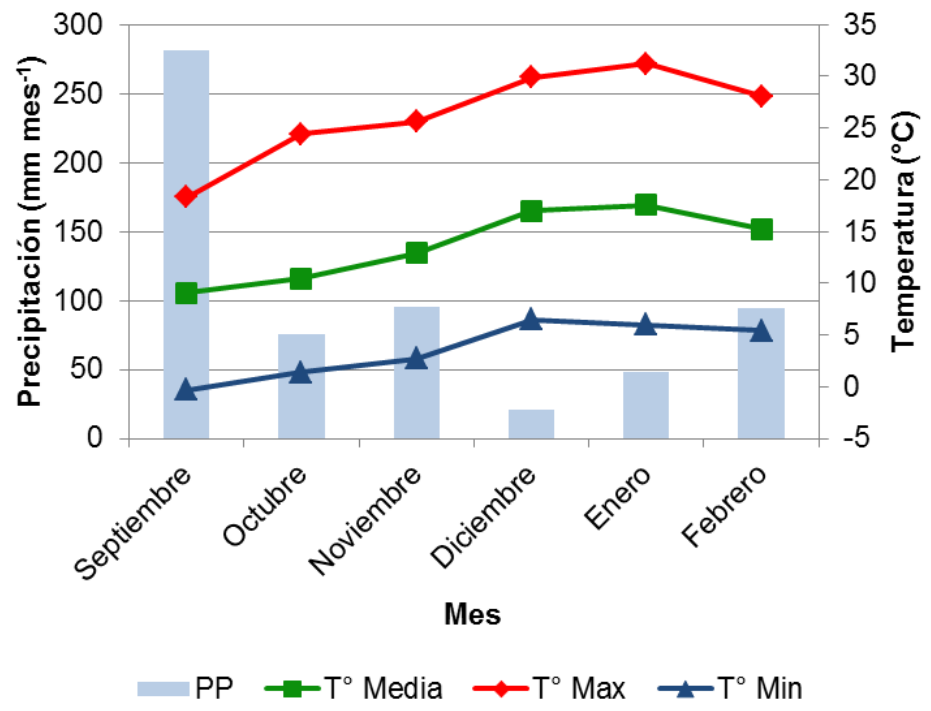

Figura 1. Precipitacion mensual (mm), temperatura promedio mensual y temperatura mínima y máxima mensual (Estación meteorológica, Estación Experimental Agropecuaria Austral, Universidad Austral de Chile).

Figure 1. Monthly precipitation ( $\mathrm{mm}$ ), average monthly temperature and monthly minimum and maximum temperature (Meteorological Station, Estación Experimental Agropecuaria Austral, Universidad Austral de Chile).

Cuadro 1. Contenido de nutrientes del suelo al inicio del experimento.

Table 1. Soil nutrient content at the beginning of the experiment.

\begin{tabular}{|c|c|c|}
\hline Parámetro & Unidad & Valor \\
\hline pH en agua & $1: 2,5$ & 5,6 \\
\hline $\mathrm{pH} \mathrm{CaCl}_{2}(0,01 \mathrm{M})$ & $1: 2,5$ & 4,9 \\
\hline Materia orgánica & $(\%)$ & 18,2 \\
\hline $\mathrm{N}$-mineral $\left(\mathrm{N}-\mathrm{NO}_{3}+\mathrm{NH}_{4}\right)$ & $\left(\mathrm{mg} \mathrm{kg}^{-1}\right)$ & 14,0 \\
\hline Fosforo Olsen & $\left(\mathrm{mg} \mathrm{kg}^{-1}\right)$ & 22,5 \\
\hline Potasio intercambiable & $\left(\mathrm{mg} \mathrm{kg}^{-1}\right)$ & 82 \\
\hline Sodio intercambiable & $\left(\mathrm{cmol}_{(+)} \mathrm{kg}^{-1}\right)$ & 0,07 \\
\hline Calcio intercambiable & $\left(\mathrm{cmol}_{(+)} \mathrm{kg}^{-1}\right)$ & 3,15 \\
\hline Magnesio intercambiable & $\left(\mathrm{cmol}_{(+)} \mathrm{kg}^{-1}\right)$ & 1,02 \\
\hline Suma de bases intercambiables & $\left(\mathrm{cmol}_{(+)} \mathrm{kg}^{-1}\right)$ & 4,45 \\
\hline Aluminio intercambiable & $\left(\mathrm{cmol}_{(+)} \mathrm{kg}^{-1}\right)$ & 0,18 \\
\hline CICE & $\left(\mathrm{cmol}_{(+)} \mathrm{kg}^{-1}\right)$ & 4,63 \\
\hline Saturación de aluminio & $(\%)$ & 3,9 \\
\hline
\end{tabular}

\section{Diseño experimental}

Se utilizó un diseño de bloques completos al azar con un arreglo factorial de dos frecuencias de defoliación ( 2 y 3 hojas) y cinco dosis de fertilización nitroge- nada $\left(0,75,150,300\right.$ y $450 \mathrm{~kg}$ de $\mathrm{N} \mathrm{ha}^{-1}$ año $\left.^{-1}\right)$, distribuidos en tres bloques. El tamaño de las parcelas fue $12,5 \mathrm{~m}^{2}$ (5 $\mathrm{m}$ de largo por 2,5 $\mathrm{m}$ de ancho). La cosecha de la pradera se realizó cuando las parcelas alcanzaron las dos o tres hojas según correspondió. La fertilización nitrogenada fue aplicada utilizando el fertilizante comercial Nitram que contiene un $27 \%$ de $\mathrm{N}$, del cual el $50 \%$ es nítrico y $50 \%$ amoniacal. La parcialización de la fertilización nitrogenada fue de acuerdo a la tasa de crecimiento de la pradera, medida para el mismo sitio en años anteriores (Balocchi et al., 2001).

La curva de extracción de $\mathrm{N}$ se obtuvo a partir de ensayos realizados anteriormente en la misma localidad. La fertilización nitrogenada se realizó mensualmente en la misma proporción del crecimiento mensual de la pradera, como se indica en el Cuadro 2. La fertilización se realizó en forma parcializada los días primero de cada mes según la dosis correspondiente.

\section{Evaluaciones}

Previo a cada corte de evaluación del rendimiento, se cortaron los bordes de la parcela $(53 \mathrm{~cm})$ con cortadora de césped dejando $5 \mathrm{~cm}$ de residuo, de esta forma las parcelas quedaron con un área de 5,67 m² (1,44 m de ancho por 3,94 m de largo), área que efectivamente fue evaluada.

\section{Rendimiento}

Se cosechó la fitomasa de cada parcela y fue pesada para obtener el peso fresco, luego se tomó de cada par- 
Cuadro 2. Proporción de la extracción mensual de nitrógeno para Lolium perenne L. y dosis mensual de nitrógeno aplicado.

Table 2. Proportion of the monthly extraction of nitrogen for Lolium perenne L. and monthly dose of applied nitrogen.

\begin{tabular}{|c|c|c|c|c|c|c|}
\hline \multirow{3}{*}{ Mes } & \multirow{3}{*}{$\begin{array}{c}\text { Extracción } \\
\% \mathrm{~N} \\
\end{array}$} & \multirow{2}{*}{\multicolumn{5}{|c|}{$\begin{array}{c}\text { Niveles de Nitrógeno } \\
\text { kg N ha-1 }^{-1}\end{array}$}} \\
\hline & & & & & & \\
\hline & & $\mathbf{0}$ & 75 & 150 & 300 & 450 \\
\hline SEPTIEMBRE & 10,7 & 0 & 8,04 & 16,08 & 32,16 & 48,24 \\
\hline OCTUBRE & 14,2 & 0 & 10,62 & 21,23 & 42,47 & 63,70 \\
\hline NOVIEMBRE & 14,7 & 0 & 11,03 & 22,06 & 44,11 & 66,17 \\
\hline DICIEMBRE & 11,0 & 0 & 8,23 & 16,45 & 32,90 & 49,35 \\
\hline ENERO & 9,6 & 0 & 7,17 & 14,35 & 28,69 & 43,03 \\
\hline FEBRERO & 5,0 & 0 & 3,74 & 7,48 & 14,97 & 22,45 \\
\hline MARZO & 4,5 & 0 & 3,38 & 6,77 & 13,53 & 20,30 \\
\hline ABRIL & 10,1 & 0 & 7,56 & 15,12 & 30,24 & 45,36 \\
\hline MAYO & 6,2 & 0 & 4,66 & 9,32 & 18,64 & 27,95 \\
\hline JUNIO & 5,8 & 0 & 4,35 & 8,69 & 17,39 & 26,08 \\
\hline JULIO & 3,9 & 0 & 2,91 & 5,81 & 11,63 & 17,44 \\
\hline AGOSTO & 4,4 & 0 & 3,32 & 6,64 & 13,28 & 19,92 \\
\hline
\end{tabular}

Nota: el área sombrada abarca el tiempo de experimentación.

$\%$ N : Porcentaje de extracción mensual de nitrógeno de la pradera, en relación al total anual.

cela una muestra del forraje verde y se llevó a horno de aire forzado a $60^{\circ} \mathrm{C}$ por 48 horas. Esto se pesó y se calculó el porcentaje y el rendimiento de MS ( $\mathrm{kg} \mathrm{MS} \mathrm{ha}^{-1}$ ), finalmente se sumaron los rendimientos de cada corte para obtener el rendimiento acumulado del periodo de experimental.

\section{Calidad Nutritiva}

La muestra seca obtenida en el análisis de rendimiento, de cada parcela, se utilizó para evaluar su calidad nutritiva mediante espectroscopia del infrarrojo cercano (NIRS) en el Laboratorio de Nutrición Animal de la Universidad Austral de Chile. Los análisis realizados fueron: Proteína Cruda (PC, \%), Energía Metabolizable (EM, Mcal kg-1 MS), Fibra Detergente Neutra (FDN, \%), Fibra Detergente Ácida (FDA, \%), N Insoluble en Fibra Detergente Neutra (FDNIN \%), Proteína Soluble (PS, \%) y Carbohidratos Solubles (CHOS, $\mathrm{g} \mathrm{kg}^{-1} \mathrm{MS}$ ).

\section{Densidad de Macollos}

A mediados de primavera (24 de Octubre) y de verano (16 de Enero) se extrajeron en forma aleatoria, en cada parcela, tres cilindros de suelo ("cores") utilizando un sacabocado de $78 \mathrm{~cm}^{2}$ de área. En cada cilindro se contaron y cortaron a ras de suelo los macollos de $L$. perenne como los de otras gramíneas. Luego se prome- dió los valores de los tres cilindros de cada parcela y se estimó el número de macollos de L. perenne y de otras gramíneas por $\mathrm{m}^{2}$.

\section{Análisis Estadístico}

Los datos fueron analizados utilizando el programa estadístico Statgraphics Plus 5,1. Para todas las variables se determinó normalidad de los datos y homogeneidad de varianza, posteriormente se realizó una ANDEVA para el diseño mencionado. Se determinó la existencia de interacción entre los factores y la existencia de diferencias entre factores, de existir estas se realizó el test de Tukey, al 1 o 5\% según el nivel de significancia.

\section{RESULTADOS}

\section{Rendimiento de Fitomasa}

Se encontró interacción significativa $(\mathrm{p}<0,05)$ entre frecuencias de defoliación y nivel de fertilización nitrogenada. Esta interacción se explica fundamentalmente por el comportamiento del tratamiento de $75 \mathrm{~kg} \mathrm{~N} \mathrm{ha}^{-1}$ año ${ }^{-1}$, que mostró una tendencia diferente al resto de los niveles de fertilización nitrogenada. En este caso la producción de fitomasa fue menor a una defoliación de tres hojas, en cambio los demás niveles de fertilización 
nitrogenada obtuvieron los mayores rendimientos con mayor frecuencia de defoliación como se observa en la Figura 2. También se observa que a medida que aumenta el nivel de fertilización, salvo para el nivel de $75 \mathrm{~kg}$ $\mathrm{N} \mathrm{ha}^{-1} \mathrm{año}^{-1}$, aumenta el rendimiento de materia seca.

En el Cuadro 3 se observa el aumento en el rendimiento a medida que aumenta el nivel de fertilización nitrogenada, esta variable presentó diferencias altamente significativas $(p<0,01)$.

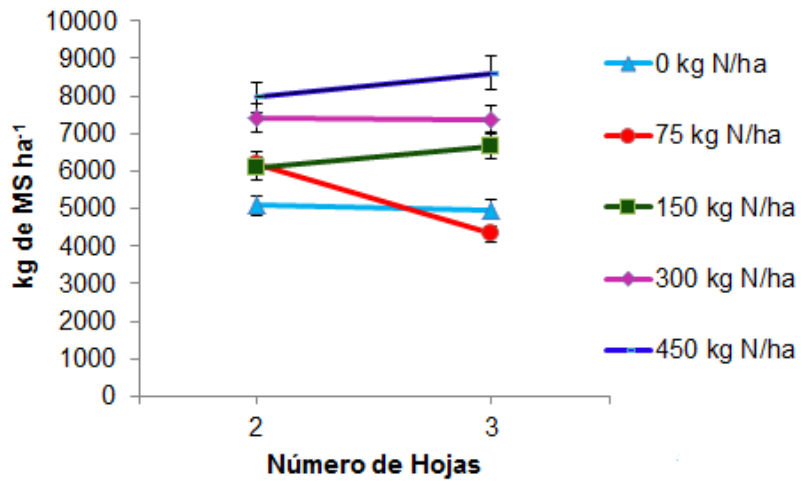

Figura 2. Interacción entre frecuencia de defoliación y nivel de fertilización nitrogenada. Barras de error representa el error estándar del promedio $(n=3)$.

Figure 2. Interaction between defoliation frequency and nitrogen fertilization level. Errors bars represent standard error of the mean $(n=3)$.

Cuadro 3. Efecto de la frecuencia de defoliación y fertilización nitrogenada sobre la producción de materia seca.

Table 3. Effect of the defoliation frequency and nitrogen fertilization level on the dry matter yield.

\begin{tabular}{|c|c|c|}
\hline $\begin{array}{c}\text { Nivel de nitrógeno } \\
\left(\mathrm{kg} \mathrm{ha}^{-1}\right)\end{array}$ & $\begin{array}{c}\text { Frecuencia de } \\
\text { defoliación }\end{array}$ & $\begin{array}{c}\text { Rendimiento } \\
\left(\text { kg MS ha }^{-1}\right)\end{array}$ \\
\hline 0 & 2 & $4861 \mathrm{~g}$ \\
\hline 75 & 2 & 5839 efg \\
\hline 150 & 2 & 6520 cde \\
\hline 300 & 2 & 7558 bc \\
\hline 450 & 2 & $7816 \mathrm{ab}$ \\
\hline 0 & 3 & $5204 \mathrm{fg}$ \\
\hline 75 & 3 & $4687 \mathrm{~g}$ \\
\hline 150 & 3 & 6234 def \\
\hline 300 & 3 & 7262 bcd \\
\hline 450 & 3 & 8766 a \\
\hline
\end{tabular}

Valores seguidos de diferente letra dentro de cada columna difieren estadísticamente ( $5 \%$ Tukey).
El mayor rendimiento de fitomasa se logró con 450 $\mathrm{kg} \mathrm{N} \mathrm{ha}^{-1}$ año ${ }^{-1}$ con las dos frecuencias de corte, en tanto que el menor rendimiento se obtuvo con el nivel $0 \mathrm{~kg}$ $\mathrm{N} \mathrm{ha}^{-1}$ año-1 y $75 \mathrm{~kg} \mathrm{~N} \mathrm{ha}^{-1}$ año $^{-1}$ en las frecuencia de defoliación con 2 hojas y 3 hojas, como se ve en la Figura 3 y 4 . No se encontraron diferencias significativas para frecuencia de defoliación. Como se observa en la Figura 2 , la producción fue numéricamente superior para la frecuencia de tres hojas en 0, 150 y $450 \mathrm{~kg} \mathrm{MS} \mathrm{ha}^{-1} \mathrm{y}$ fue mayor para dos hojas en los dos tratamientos 75 y 300 kg MS ha-1.

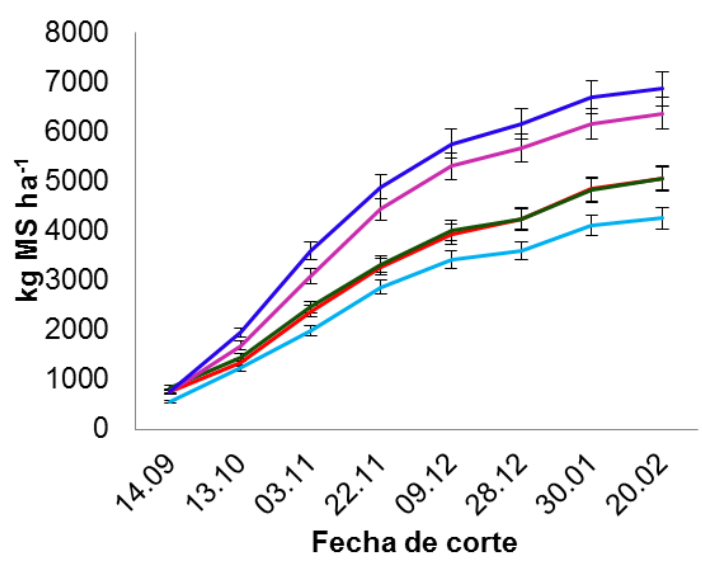

Figura 3. Evolución de la producción de fitomasa con frecuencia de defoliación de 2 hojas. Barras de error representa el error estándar del promedio $(n=3)$.

Figure 3. Evolution of the herbage production with 2 leaf defoliation frequently. Errors bars represent standard error of the mean $(n=3)$.

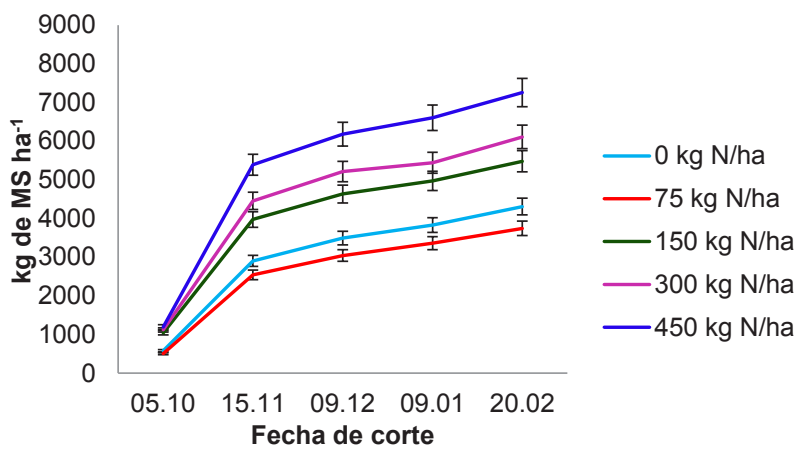

Figura 4. Evolución de la producción de fitomasa con frecuencia de defoliación de 3 hojas. Barras de error representa el error estándar del promedio $(n=3)$.

Figure 4. Evolution of the herbage production with 3 leaf defoliation frequently. Errors bars represent standard error of the mean $(n=3)$. 


\section{Calidad Nutritiva}

En la Figura 5 se observa la producción acumulada de PC por hectárea para la defoliación con dos hojas, se ve que a medida que aumenta la fertilización nitrogenada también aumenta la producción de PC por hectárea.

No ocurre lo mismo para el tratamiento de defoliación con tres hojas (Figura 6) donde la menor producción de PC se observó en el nivel de 75 y 0 kg de $\mathrm{N} \mathrm{ha}^{-1}$ año $0^{-1}$, luego aumenta para el nivel de fertilización 150 , 300 y $450 \mathrm{~kg}$ de $\mathrm{N} \mathrm{ha}^{-1} \mathrm{año}^{-1}$. En el Cuadro 5 se presenta la concentración de PC en la materia seca para cada

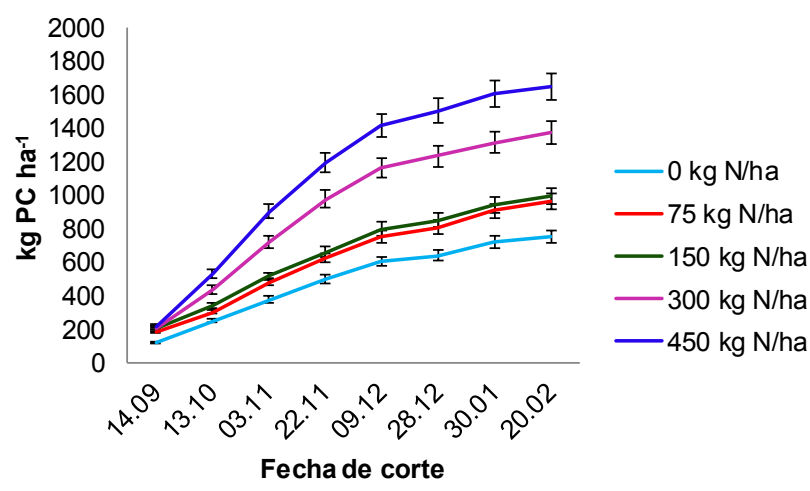

Figura 5. Evolución de la producción de proteína cruda por hectárea con frecuencia de defoliación de 2 hojas. Barras de error representa el error estándar del promedio $(n=3)$.

Figure 5. Evolution of crude protein production per hectare with 2 leaf defoliation frequently. Errors bars represent standard error of the mean $(n=3)$.

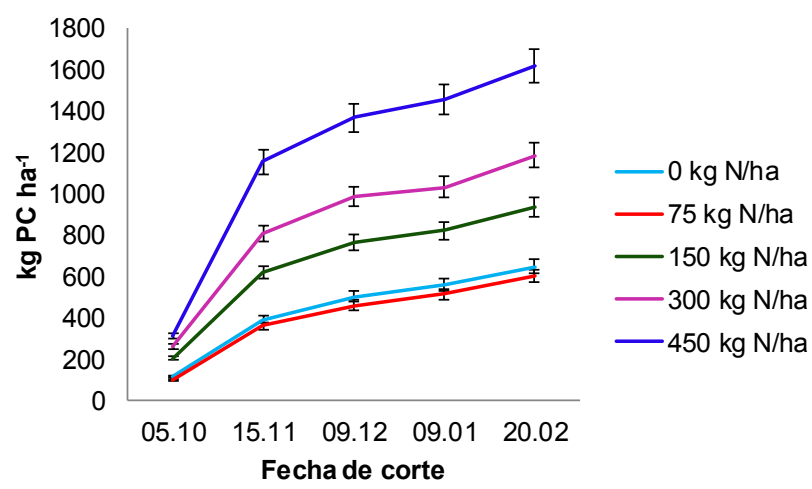

Figura 6. Evolución de la producción de proteína cruda por hectárea con frecuencia de defoliación de 3 hojas. Barras de error representa el error estándar del promedio $(n=3)$.

Figure 6. Evolution of crude protein production per hectare with 3 leaf defoliation frequently. Errors bars represent standard error of the mean $(n=3)$. corte según el nivel de fertilización nitrogenado. En los primeros cuatro cortes hubo diferencias altamente significativas y en los siguientes cuatro cortes solo diferencias significativas.

Para el primer corte no hubo diferencias significativas entre los niveles de 300 y $450 \mathrm{~kg} \mathrm{~N} \mathrm{ha}^{-1} \mathrm{año}^{-1}$, ni entre los niveles de 75 y $150 \mathrm{~kg} \mathrm{~N} \mathrm{ha}^{-1} \mathrm{año}^{-1}$. Estos últimos tuvieron una menor concentración de PC que 300 y $450 \mathrm{~kg} \mathrm{~N} \mathrm{ha}^{-1} \mathrm{año}^{-1}$. El nivel $0 \mathrm{~kg} \mathrm{~N} \mathrm{ha}^{-1} \mathrm{año}^{-1}$ fue distinto de todos y obtuvo la menor concentración de PC. En el segundo corte hay menores diferencias entre grupos, el nivel de $450 \mathrm{~kg} \mathrm{~N} \mathrm{ha}^{-1}$ año-1 tiene el mayor porcentaje de PC, pero no tiene diferencias con el nivel $300 \mathrm{~kg} \mathrm{~N} \mathrm{ha}^{-1} \mathrm{año}^{-1}$, este último no presenta diferencias con el nivel $150 \mathrm{~kg} \mathrm{~N} \mathrm{ha}^{-1} \mathrm{año}^{-1} \mathrm{y}$ el nivel de fertilización $150 \mathrm{~kg} \mathrm{~N} \mathrm{ha}^{-1}$ año ${ }^{-1}$ no tiene diferencias con los niveles de 0 y $75 \mathrm{~kg} \mathrm{~N} \mathrm{ha}^{-1}$ año ${ }^{-1}$, teniendo estos últimos las menores concentraciones de PC. En el tercer corte no hay diferencias entre el nivel 450 y $300 \mathrm{~kg} \mathrm{~N} \mathrm{ha}^{-1} \mathrm{año}^{-1}$, y el nivel $300 \mathrm{~kg} \mathrm{~N}$ ha $^{-1}$ año $0^{-1}$ es igual al tratamiento 150,75 y $0 \mathrm{~kg} \mathrm{~N} \mathrm{ha}^{-1}$ año ${ }^{-1}$. Al cuarto corte, el tratamiento $450 \mathrm{y}$ $300 \mathrm{~kg} \mathrm{~N} \mathrm{ha}^{-1} \mathrm{año}^{-1}$ son iguales y los más altos en PC, el tratamiento 300,150 y $75 \mathrm{~kg} \mathrm{~N} \mathrm{ha}^{-1}$ año ${ }^{-1}$ son iguales, y también son iguales el tratamiento 0,75 y $150 \mathrm{~kg} \mathrm{~N}^{-1}$ año ${ }^{-1}$. En el corte número cinco no hay diferencias entre $0,75,150$ y $300 \mathrm{~kg} \mathrm{~N} \mathrm{ha}^{-1} \mathrm{año}^{-1}$, tampoco las hay entre 150,300 y $450 \mathrm{~kg} \mathrm{~N} \mathrm{ha}^{-1} \mathrm{año}^{-1}$. En el sexto corte el tratamiento 450 y $150 \mathrm{~kg} \mathrm{~N} \mathrm{ha}^{-1} \mathrm{año}^{-1}$ no tienen diferencias, aunque el nivel $450 \mathrm{~kg} \mathrm{~N}^{-1} \mathrm{año}^{-1}$ se mantiene como el más elevado en $\mathrm{PC}$, el nivel de $300 \mathrm{~kg} \mathrm{~N}^{-1}$ tuvo menor PC que en nivel de $150 \mathrm{~kg} \mathrm{~N}^{-1}$ y los tratamientos 0 , 75,150 y $300 \mathrm{~kg} \mathrm{~N} \mathrm{ha}^{-1}$ año-1 son iguales. En el séptimo corte los tratamientos $0,75,150$ y $300 \mathrm{~kg} \mathrm{~N} \mathrm{ha}^{-1}$ año${ }^{1}$ no presentan diferencias y tampoco el de 300 y 450 $\mathrm{kg} \mathrm{N} \mathrm{ha}^{-1}$ año $^{-1}$. En el último corte solo hay diferencias entre el tratamiento 0 y $450 \mathrm{~kg} \mathrm{~N} \mathrm{ha}^{-1} \mathrm{año}^{-1}$, no presentando los tratamientos intermedios diferencias con los tratamientos 0 y $450 \mathrm{~kg} \mathrm{~N}$ ha $^{-1} \mathrm{año}^{-1}$ (Cuadro 4).

En el nivel de defoliación de tres hojas hubo diferencias altamente significativas entre los cinco cortes realizados. En el primero de ellos no hay diferencias entre el nivel de 450 y $300 \mathrm{~kg} \mathrm{~N}^{-1} \mathrm{año}^{-1}$ y en los niveles 75, 150 y $300 \mathrm{~kg} \mathrm{~N} \mathrm{ha}^{-1} \mathrm{año}^{-1}$. Tampoco las hay entre 0,75 y $150 \mathrm{~kg} \mathrm{~N} \mathrm{ha}^{-1}$ año $^{-1}$. En el segundo corte en nivel de $450 \mathrm{~kg} \mathrm{~N} \mathrm{ha}^{-1}$ año ${ }^{-1}$ es distinto de todos los demás, en nivel de 300 y $150 \mathrm{~kg} \mathrm{~N} \mathrm{ha}^{-1} \mathrm{año}^{-1}$ son iguales, y también los niveles de 0,75 y $150 \mathrm{~kg} \mathrm{~N} \mathrm{ha}^{-1} \mathrm{año}^{-1}$. En el tercer corte ocurre que el tratamiento de $450 \mathrm{~kg} \mathrm{~N} \mathrm{ha}^{-1} \mathrm{año}^{-1}$ es distinto de todos, los de 300 y $150 \mathrm{~kg} \mathrm{~N}^{-1} \mathrm{año}^{-1}$ son iguales, el de $150 \mathrm{~kg} \mathrm{~N} \mathrm{ha}^{-1}$ año-1 es igual al de 75 $\mathrm{kg} \mathrm{N} \mathrm{ha-1} \mathrm{año}^{-1}$ y este último igual al nivel $0 \mathrm{~kg} \mathrm{~N} \mathrm{ha}^{-1}$ año $0^{-1}$. En el cuarto corte el nivel de fertilización $450 \mathrm{~kg}$ $\mathrm{N} \mathrm{ha}^{-1}$ año $^{-1}$ fue igual a $300 \mathrm{~kg} \mathrm{~N} \mathrm{ha}^{-1} \mathrm{año}^{-1}$, luego 300 $\mathrm{kg} \mathrm{N} \mathrm{ha}^{-1}$ año ${ }^{-1}$ tuvo iguales resultados que 150 y $75 \mathrm{~kg}$ $\mathrm{N} \mathrm{ha}^{-1}$ año ${ }^{-1}$ y además $150 \mathrm{~kg} \mathrm{~N} \mathrm{ha}^{-1}$ año ${ }^{-1}$ fue igual a 75 y 0 $\mathrm{kg} \mathrm{N} \mathrm{ha-1}$ año ${ }^{-1}$. En el último corte el mayor porcentaje 
de PC fue para el tratamiento $450 \mathrm{~kg} \mathrm{~N} \mathrm{ha}^{-1}$ año ${ }^{-1}$ que fue significativamente mayor que el tratamiento $0 \mathrm{~kg}$ $\mathrm{N} \mathrm{ha}^{-1}$ año-1 mostrando los otros tratamientos un comportamiento intermedio.

El nivel de fertilización $\mathrm{N}$ afectó el porcentaje de MS, se observa en el Cuadro 6 que el tratamiento con menor nivel de fertilización tuvo el mayor porcentaje de MS, y la tendencia fue igual para todos los tratamientos, a medida que aumentó la fertilización disminuyó el porcentaje de MS. Los niveles de fertilización de 300 y $450 \mathrm{~kg} \mathrm{~N} \mathrm{ha}^{-1}$ año ${ }^{-1}$ no presentaron diferencias, el nivel de fertilización de $300 \mathrm{~kg} \mathrm{~N} \mathrm{ha}^{-1}$ año $0^{-1}$ es igual al nivel de $150 \mathrm{~kg} \mathrm{~N} \mathrm{ha}^{-1}$ año $^{-1}$ y este último es igual al nivel de 75 $\mathrm{kg} \mathrm{N} \mathrm{ha}^{-1}$ año-1 que estadísticamente es igual al nivel de 0 kg N ha ${ }^{-1}$ año ${ }^{-1}$.

La frecuencia de defoliación modificó el porcentaje de PC, ésta fue mayor con la defoliación a dos hojas. El nivel de fertilización también afectó la PC, el mayor contenido se obtuvo con el nivel de fertilización de 450 $\mathrm{kg} \mathrm{N} \mathrm{ha}^{-1}$ año $^{-1}$ y distinto de los demás, seguidos de 300 y $150 \mathrm{~kg} \mathrm{~N} \mathrm{ha}^{-1}$ año $^{-1}$, ambos distintos. El nivel de fertilización $150 \mathrm{~kg} \mathrm{~N} \mathrm{ha}^{-1} \mathrm{año}^{-1}$ fue igual al nivel $75 \mathrm{~kg} \mathrm{~N}$ $\mathrm{ha}^{-1} \mathrm{año}^{-1} \mathrm{y}$ este último fue igual al nivel $0 \mathrm{~kg} \mathrm{~N} \mathrm{ha}^{-1} \mathrm{año}^{-1}$ (Cuadro 6).

Entre las dos frecuencias de defoliación no existieron diferencias en la EM, pero ésta sí cambió según

Cuadro 4. Variaciones en el contenido de proteína cruda, según nivel de fertilización nitrogenada en cada corte para frecuencia de defoliación de dos hojas.

Table 4. Variations in the crude protein content, according to nitrogen fertilization level in each cut for two-leaf defoliation frequency.

\begin{tabular}{ccccccccc}
\hline $\begin{array}{c}\text { Nivel de N } \\
\text { (kg N ha }^{-1} \text { ) }\end{array}$ & Corte 1 & Corte2 & Corte 3 & Corte 4 & Corte $\mathbf{5}$ & Corte 6 & Corte 7 & Corte 8 \\
\hline 0 & $22,0 \mathrm{c}$ & $18,6 \mathrm{c}$ & $16,5 \mathrm{~b}$ & $14,2 \mathrm{c}$ & $18,5 \mathrm{~b}$ & $19,4 \mathrm{~b}$ & $15,7 \mathrm{~b}$ & $23,2 \mathrm{~b}$ \\
75 & $23,9 \mathrm{~b}$ & $20,5 \mathrm{c}$ & $17,4 \mathrm{~b}$ & $15,8 \mathrm{bc}$ & $19,0 \mathrm{~b}$ & $19,0 \mathrm{~b}$ & $15,4 \mathrm{~b}$ & $24,2 \mathrm{ab}$ \\
150 & $24,5 \mathrm{~b}$ & $21,5 \mathrm{bc}$ & $17,4 \mathrm{~b}$ & $16,7 \mathrm{bc}$ & $20,6 \mathrm{ab}$ & $20,4 \mathrm{ab}$ & $15,6 \mathrm{~b}$ & $25,4 \mathrm{ab}$ \\
300 & $27,3 \mathrm{a}$ & $24,4 \mathrm{ab}$ & $20,1 \mathrm{ab}$ & $19,2 \mathrm{ab}$ & $20,8 \mathrm{ab}$ & $19,9 \mathrm{~b}$ & $16,9 \mathrm{ab}$ & $25,8 \mathrm{ab}$ \\
450 & $28,8 \mathrm{a}$ & $25,9 \mathrm{a}$ & $22,9 \mathrm{a}$ & $22,6 \mathrm{a}$ & $25,2 \mathrm{a}$ & $23,3 \mathrm{a}$ & $17,8 \mathrm{a}$ & $27,4 \mathrm{a}$ \\
$\mathrm{NS}$ & $* *$ & $* *$ & $* *$ & $* *$ & $*$ & $*$ & $*$ & $*$ \\
\hline
\end{tabular}

Letras distintas indican diferencias significativas.

NS: Nivel de significancia.

*: Diferencias significativas ( $\mathrm{p}$-valor $<0,05$ ).

**: Diferencias altamente significativas (p-valor $<0,01$ ).

Cuadro 5. Variaciones en el contenido de proteína cruda, según nivel de fertilización nitrogenada en cada corte para frecuencia de defoliación de tres hojas.

Table 5. Variations in the crude protein content, according to nitrogen fertilization level in each cut for three-leaf defoliation frequency.

\begin{tabular}{|c|c|c|c|c|c|}
\hline $\begin{array}{l}\text { Nivel de N } \\
\left(\mathrm{kg} \mathrm{N} \mathrm{ha}^{-1}\right)\end{array}$ & $\begin{array}{c}\text { Corte } 1 \\
05.10\end{array}$ & $\begin{array}{c}\text { Corte } 2 \\
15.11\end{array}$ & $\begin{array}{c}\text { Corte } 3 \\
09.12\end{array}$ & $\begin{array}{c}\text { Corte } 4 \\
09.01\end{array}$ & $\begin{array}{c}\text { Corte } 5 \\
20.02\end{array}$ \\
\hline 0 & $18,9 \mathrm{c}$ & $12,1 \mathrm{c}$ & $18,5 \mathrm{~d}$ & $16,3 \mathrm{c}$ & $18,6 \mathrm{~b}$ \\
\hline 75 & 19,6 bc & $12,8 \mathrm{c}$ & $19,5 \mathrm{~cd}$ & $17,8 \mathrm{bc}$ & $21,9 \mathrm{ab}$ \\
\hline 150 & $19,3 \mathrm{bc}$ & $14,2 \mathrm{bc}$ & $21,6 \mathrm{bc}$ & $17,2 \mathrm{bc}$ & $22,1 \mathrm{ab}$ \\
\hline 300 & $23,2 \mathrm{ab}$ & $16,3 \mathrm{~b}$ & $23,6 \mathrm{~b}$ & $19,3 \mathrm{ab}$ & $23,6 \mathrm{ab}$ \\
\hline 400 & 25,9 a & $20,1 \mathrm{a}$ & 26,9 a & $21,0 \mathrm{a}$ & $24,7 \mathrm{a}$ \\
\hline NS & $* *$ & $* *$ & $* *$ & $* *$ & $* *$ \\
\hline
\end{tabular}

Letras distintas indican diferencias significativas.

NS: Nivel de significancia.

**: Diferencias altamente significativas ( $\mathrm{p}$-valor $<0,01$ ). 
Cuadro 6. Promedio anual (ponderado por el rendimiento), de la calidad nutritiva para una pradera de Lolium perenne L. defoliada con dos y tres hojas y con cinco niveles de fertilización nitrogenada.

Table 6. Annual average (weighted for yield), of the nutritional quality of a Lolium perenne L. sward defoliated at two or three leaves with five levels of nitrogen fertilization.

\begin{tabular}{|c|c|c|c|c|c|c|c|c|}
\hline & $\begin{array}{l}\text { MS } \\
(\%)\end{array}$ & $\begin{array}{l}\text { PC } \\
(\%)\end{array}$ & $\begin{array}{c}\text { EM } \\
(\text { Mcal kg-1) }\end{array}$ & $\begin{array}{l}\text { FDN } \\
(\%)\end{array}$ & $\begin{array}{l}\text { FDA } \\
(\%)\end{array}$ & $\begin{array}{c}\text { FDNIN } \\
(\%)\end{array}$ & $\begin{array}{c}\text { PS } \\
(\%)\end{array}$ & $\begin{array}{r}\text { CHOS } \\
\left(\mathrm{g} \mathrm{kg}^{-1}\right)\end{array}$ \\
\hline \multicolumn{9}{|c|}{ Nivel de nitrógeno $\left(\mathrm{kg} \mathrm{ha}^{-1}\right)$} \\
\hline 0 & $24,5 \mathrm{a}$ & $16,3 \mathrm{~d}$ & $2,56 \mathrm{~d}$ & $40,0 \mathrm{a}$ & $26,4 \mathrm{a}$ & $0,82 \mathrm{c}$ & $9,1 \mathrm{c}$ & $99,8 \mathrm{a}$ \\
\hline 75 & $23,1 \mathrm{ab}$ & $17,4 \mathrm{~cd}$ & $2,59 \mathrm{~cd}$ & $39,8 \mathrm{a}$ & $26,4 \mathrm{a}$ & $0,86 \mathrm{c}$ & $9,3 \mathrm{c}$ & $97,9 \mathrm{ab}$ \\
\hline 150 & $22,4 \mathrm{bc}$ & $18,36 \mathrm{c}$ & $2,62 \mathrm{bc}$ & $38,8 \mathrm{a}$ & $25,9 a$ & $0,90 \mathrm{bc}$ & $9,6 \mathrm{bc}$ & $98,1 \mathrm{ab}$ \\
\hline 300 & $21,0 \mathrm{~cd}$ & $20,4 \mathrm{~b}$ & $2,67 \mathrm{ab}$ & $37,9 \mathrm{a}$ & $25,3 \mathrm{a}$ & $0,99 \mathrm{~b}$ & $10,5 \mathrm{~b}$ & $89,3 \mathrm{ab}$ \\
\hline 450 & $20,8 \mathrm{~d}$ & $23,1 \mathrm{a}$ & $2,70 \mathrm{a}$ & $35,3 \mathrm{~b}$ & $24,1 \mathrm{~b}$ & $1,14 \mathrm{a}$ & $12,0 \mathrm{a}$ & $87,5 \mathrm{~b}$ \\
\hline Nivel de significancia & $* *$ & $* *$ & $* *$ & $* *$ & $* *$ & $* *$ & $* *$ & $*$ \\
\hline \multicolumn{9}{|l|}{ Frecuencia de defoliación } \\
\hline 2 hojas & $22,8 \mathrm{a}$ & 20,3 a & 2,6 & $36,8 \mathrm{~b}$ & $24,5 \mathrm{~b}$ & $1,0 \mathrm{a}$ & $10,7 \mathrm{a}$ & 94,1 \\
\hline 3 hojas & $22,9 \mathrm{a}$ & $17,9 \mathrm{~b}$ & 2,6 & $39,8 \mathrm{a}$ & $26,7 \mathrm{a}$ & $0,8 \mathrm{~b}$ & $9,5 \mathrm{~b}$ & 95,0 \\
\hline Nivel de significancia & NS & $* *$ & NS & $* *$ & $* *$ & $* *$ & $* *$ & NS \\
\hline
\end{tabular}

MS: Materia seca; PC: Proteína cruda; EM: Energía metabolizable; FDN: Fibra detergente neutro; FDA: Fibra detergente ácida; FDNIN: Nitrógeno Insoluble en Fibra Detergente Neutra; PS: Proteína soluble; CHOS: Carbohidratos solubles. NS: no significativo.

*: Diferencias significativas ( $\mathrm{p}$-valor $<0,05$ ).

**: Diferencias altamente significativas (p-valor $<0,01$ ).

Valores seguidos de diferente letra dentro de cada columna difieren estadísticamente ( $5 \%$ Tukey).

el nivel de fertilización nitrogenada y aumentó con la mayor fertilización nitrogenada. El FDN y FDA disminuyen a medida que aumenta el nivel de fertilización. Sin embargo, solo hay diferencias significativas con el nivel de fertilización de $450 \mathrm{~kg} \mathrm{~N} \mathrm{ha}^{-1}$ año ${ }^{-1}$ el que tiene los menores contenidos de FDA y FDN. En relación a la frecuencia de defoliación el tratamiento de tres hojas fue el que mostró mayor contenido de FDN y FDA (Cuadro 6).

El FDNIN fue mayor con la defoliación a dos hojas, como se observa en el Cuadro 6. El FDNIN aumentó con el mayor nivel de fertilización nitrogenada $(450 \mathrm{~kg} \mathrm{~N}$ $\mathrm{ha}^{-1} \mathrm{año}^{-1}$ ) y superior del nivel $300 \mathrm{~kg} \mathrm{~N} \mathrm{ha}^{-1} \mathrm{año}^{-1}$, este es igual al nivel $150 \mathrm{~kg} \mathrm{~N} \mathrm{ha}^{-1} \mathrm{año}^{-1}$.

La PS fue mayor en el tratamiento defoliado con dos hojas. La PS también cambia según el nivel de fertilización nitrogenada y es mayor con el nivel de $450 \mathrm{~kg} \mathrm{~N}$ ha $^{-1}$ año $^{-1}$. Los niveles de fertilización 300 y el de 150 $\mathrm{kg} \mathrm{N} \mathrm{ha}^{-1}$ año-1 fueron iguales. Los tratamientos fertilizados con 0,75 y $150 \mathrm{~kg} \mathrm{~N}^{-1} \mathrm{ha}^{-1}$ año $^{-1}$ no presentan diferencias es su nivel de PS.

El nivel de CHOS no presentó diferencias significativas entre las dos frecuencias de defoliación, pero sí en los distintos niveles de fertilización nitrogenada y fue mayor con las dosis menores de $\mathrm{N}$, aunque no hubo diferencias entre los niveles $0,75,150$ y $300 \mathrm{~kg} \mathrm{~N} \mathrm{ha}^{-1}$ año ${ }^{-1}$. Por otra parte el nivel de fertilización de $450 \mathrm{~kg}$
$\mathrm{N}$ ha ${ }^{-1}$ año ${ }^{-1}$ es el menor, pero no tiene diferencias con 300,150 y $75 \mathrm{~kg} \mathrm{~N} \mathrm{ha}^{-1}$ año $^{-1}$.

\section{Densidad de Macollos}

La densidad de macollos de L. perenne aumentó significativamente a medida que lo hace la fertilización nitrogenada, el nivel de $450 \mathrm{~kg} \mathrm{~N} \mathrm{ha}^{-1} \mathrm{año}^{-1}$ solo presentó diferencias con el nivel $0 \mathrm{~kg} \mathrm{~N} \mathrm{ha}^{-1} \mathrm{año}^{-1}$ (Cuadro 7). La densidad de macollos de otras gramíneas (principalmente Agrostis capillaris L.) y la densidad total de macollos no se afectaron por los distintos niveles de fertilización nitrogenada, porque en general la menor densidad de macollos de L. perenne en los bajos niveles de $\mathrm{N}$ es compensado por un incremento en la densidad de A. capillaris.

La frecuencia de defoliación no influyó en la densidad de macollos de L. perenne, de otras gramíneas ni del total de gramíneas. La densidad de macollos cambió entre primavera y verano en forma altamente significativa, en primavera la densidad de macollos de $L$. perenne es mayor en un $44,9 \%$ en relación al verano, ocurre lo contrario con macollos de otras gramíneas que aumentan su densidad en verano en un $5,4 \%$. La densidad total de gramíneas disminuye de primavera a verano en un $20,5 \%$. 
Cuadro 7. Densidad de macollos de Lolium perenne L., otras gramíneas y del total de gramíneas en una pradera establecida hace cuatro años, bajo dos regímenes de defoliación y cinco niveles de fertilización nitrogenada.

Table 7. Density of tillers of Lolium perenne L., other grasses and the total number of grass in a perennial sward, under two regimes of defoliation and five levels of nitrogen fertilization.

\begin{tabular}{|c|c|c|c|}
\hline Tratamiento & $\begin{array}{c}\text { Ballica } \\
\left(\mathrm{N}^{\circ} \text { macollos } \mathrm{m}^{-2}\right)\end{array}$ & $\begin{array}{l}\text { Otras gramíneas } \\
\left(\mathrm{N}^{\circ} \text { macollos } \mathrm{m}^{-2}\right)\end{array}$ & $\begin{array}{l}\text { Total gramíneas } \\
\left(\mathrm{N}^{\circ} \text { macollos } \mathrm{m}^{-2}\right)\end{array}$ \\
\hline \multicolumn{4}{|l|}{$\begin{array}{c}\text { Nivel de N } \\
\left(\text { kg N ha' }^{-1} \text { año }^{-1}\right)\end{array}$} \\
\hline 0 & $6296 \mathrm{~b}$ & 2497 & 8793 \\
\hline 75 & $6891 \mathrm{ab}$ & 2384 & 9276 \\
\hline 150 & $6921 \mathrm{ab}$ & 2282 & 9204 \\
\hline 300 & $7333 \mathrm{ab}$ & 1390 & 8723 \\
\hline 450 & 8949 a & 2042 & 10974 \\
\hline Nivel de significancia & $*$ & NS & NS \\
\hline \multicolumn{4}{|l|}{ Frecuencia defoliación } \\
\hline 2 hojas & 7521 & 1810 & 9332 \\
\hline 3 hojas & 7035 & 2420 & 9456 \\
\hline Nivel de significancia & NS & NS & NS \\
\hline \multicolumn{4}{|l|}{ Estación } \\
\hline Primavera & $10040 \mathrm{a}$ & $429 \mathrm{~b}$ & 10470 a \\
\hline Verano & $4516 \mathrm{~b}$ & 3801 a & $8318 \mathrm{~b}$ \\
\hline Nivel de significancia & $* *$ & $* *$ & $* *$ \\
\hline
\end{tabular}

Letras distintas indican diferencias significativas.

NS: Nivel de significancia.

**: Diferencias altamente significativas ( $\mathrm{p}$-valor $<0,01$ ).

\section{DISCUSIÓN}

\section{Rendimiento de fitomasa}

Las frecuencias de defoliación de dos y tres hojas no modificaron el rendimiento de fitomasa. Esto probablemente explicado por el hecho que las frecuencias de defoliación usadas en este estudio se encuentran dentro de los rangos recomendados para L. perenne. Resultados similares obtuvieron Acosta et al. (1998) y López et al. (2009) al comparar una pradera defoliada en 2,5 hojas con otra defoliada en 3,5 hojas, en tanto que Beukes et al. (2006) solo encontraron diferencias del 1\% a favor del menor intervalo de defoliación. Acharán et al. (2009) tampoco obtuvieron diferencias significativas al comparar dos frecuencias de defoliación $(2,5$ y 3,5 hojas por macollo). Turner et al. (2006a) encontraron una mayor tasa de crecimiento al defoliar con dos hojas durante la temporada primaveral y al alargar el intervalo de defoliación durante el verano.

Lestienne et al. (2006) encontraron un mayor rendimiento cuando usaron una menor frecuencia de de- foliación en el mayor nivel de fertilización nitrogenada. Clark (2011) señala que el rendimiento de fitomasa aumenta como respuesta a la fertilización nitrogenada. En este ensayo, el aumento proporcional registrado en el rendimiento a medida que aumentaba la fertilización N concuerda con lo obtenido por Bochi et al. (2009), Akmal y Janssens (2004), Niklitschek (2011).

Clark y Harris (1996) y Harris et al. (1996) al evaluar 0,200 y $400 \mathrm{~kg} \mathrm{~N} \mathrm{ha}^{-1} \mathrm{año}^{-1}$ en L. perenne, encontraron rendimientos de hasta $4480 \mathrm{~kg}$ de MS extras por hectárea producto de la fertilización con N. Hopkins et $a l$. (1990) en una pradera permanente y en condiciones de campo, obtuvieron respuestas significativas a la aplicación de $\mathrm{N}$ al aumentar el nivel de $\mathrm{N}$ hasta $450 \mathrm{~kg}$ $\mathrm{N} \mathrm{ha}^{-1} \mathrm{año}^{-1}$, sin encontrar diferencias en el rendimiento de materia seca en los niveles de fertilización entre 450 y $900 \mathrm{~kg} \mathrm{~N} \mathrm{ha}^{-1} \mathrm{año}^{-1}$. Los resultados de este estudio confirman la respuesta significativa en producción de fitomasa que tiene la pradera frente a dosis crecientes de fertilización $\mathrm{N}$ y esta información explica en gran medida la tendencia que existe actualmente entre los productores, especialmente lecheros, a incrementar los 
niveles de fertilización $\mathrm{N}$ de las praderas con el propósito de aumentar su producción de fitomasa.

\section{Calidad nutritiva}

El contenido de MS de la pradera cosechada fue menor con el mayor nivel de fertilización nitrogenada, resultados similares a los reportados por Niklitschek (2011). Este menor contenido de MS se debe en gran parte al aumento del agua interna de las hojas y a la mayor cantidad de fitomasa que retiene mayor cantidad de agua externa, como roció y lluvia (Whitehead, 1995).

El nivel de PC aumentó significativamente a medida que se incrementa la fertilización nitrogenada y aumentó la frecuencia de defoliación. Se obtuvieron los mayores valores de PC con una fertilización nitrogenada de $450 \mathrm{~kg} \mathrm{~N} \mathrm{ha}^{-1} \mathrm{año}^{-1} \mathrm{y}$ con una defoliación al estado de dos hojas, pero sin interacción entre estos factores. Los mismos resultados obtuvo Bochi et al. (2009) al comparar cuatro niveles de fertilización nitrogenada. Además, Marquéz et al. (2007), Niklitschek (2011) y Loaiza et al. (2017), también encontraron que el nivel de PC fue más alto con mayor dosis de $\mathrm{N}$ y con mayor frecuencia de defoliación.

En L. perenne (Loaiza et al., 2017) al usar dosis crecientes de $\mathrm{N}$, encontraron una respuesta directa aumentando la PC cuando aumentó la dosis de N. También aumenta el nivel de PC al aumentar la frecuencia de defoliación (Acharán et al., 2009; López et al., 2009). Este aumento de la proteína se debería a que mayores dosis de fertilización nitrogenada llevan a mayores niveles de $\mathrm{N}$ en el contenido celular, pero al mismo tiempo la pared celular es menor por lo que disminuye el nivel de carbohidratos estructurales (Hoekstra et al., 2007).

Rawnsley et al. (2001), al evaluar seis frecuencias de defoliación (1-6 hojas) en pasto ovillo (Dactylis glomerata L.), señalaron que los niveles de PC disminuyeron a medida que la planta tuvo mayor número de hojas.

El incremento en los niveles de fertilización nitrogenada aumentó significativamente la cantidad de EM producida, coincidiendo con lo reportado por Niklitschek (2011). La producción acumulada de EM para dos hojas en este estudio fue de $18968 \mathrm{Mcal} \mathrm{ha}^{-1} \mathrm{y}$ de 19600 Mcal ha-1 para tres hojas, sin encontrarse diferencias significativas, resultados similares a los reportados por Niklitschek (2011) y Turner et al. (2006b).

El FDN fue menor con mayor nivel de fertilización nitrogenada, coincidiendo estos resultados con lo reportado por Niklitschek (2011) y Hoekstra et al. (2007). El FDN aumentó con la menor frecuencia de defoliación, por la lignificación y mayor contenido de pared celular a medida que la planta madura. Los mismos resultados observó Niklitschek (2011) y Whitehead
(1995) añade que normalmente la fertilización nitrogenada tiene pequeños efectos sobre el contenido de fibra y digestibilidad del forraje bajo las mismas condiciones de defoliación y en estados inmaduros. Hoekstra et al. (2007) señala que el FDN aumenta a medida que pasan más días luego del rebrote de la pradera y Poff et al. (2011) al igual que en este estudio, obtuvo diferencias significativas en los niveles de FDN al comparar dos frecuencias de defoliación (2,5 y 3,5 hojas) siendo en su caso el valor de FDN de $33,41 \%$ y $36,86 \%$.

El contenido de FDA de la pradera fue mayor con el intervalo de defoliación de 3 hojas. Estos resultados son concordantes con los obtenidos por Niklitschek (2011) y López et al. (2009), los cuales reportaron mayores niveles de FDA al defoliar con 3,5 versus 2,5 hojas. Hoekstra et al. (2007) determinaron un aumento de la FDA con la disminución de la frecuencia de defoliación al usar tres frecuencias de defoliación (2-3, 4-5 y 6-7 semanas). Poff et al. (2011) reportó un aumento en el nivel de FDA al comparar las frecuencias de defoliación de 1,5; 2,5 y 3,5 hojas, teniendo valores que concuerdan con los obtenidos en este estudio. Hopkins et al. (1990) y Poff et al. (2011) reportaron valores de FDA entre 24 y $25 \%$ usando entre 0 y $300 \mathrm{~kg} \mathrm{~N}^{-1}$ año ${ }^{-1}$, resultados muy similares a los obtenidos en este estudio.

El contenido de CHOS en las praderas normalmente disminuye al usar fertilización nitrogenada, debido principalmente al estímulo que produce el $\mathrm{N}$ en el crecimiento y el uso de los CHOS en la formación de tejido (Whitehead, 1995). En este estudio se encontraron diferencias significativas entre distintos niveles de fertilización nitrogenada, donde el nivel de CHOS disminuyó a medida que aumentó el nivel de fertilización nitrogenada. Resultados similares obtuvieron Donaghy y Fulkerson (2002) al usar tratamientos con y sin fertilización nitrogenada y Niklitschek (2011) al usar dosis crecientes de fertilización nitrogenada. Hoekstra et al., (2007) al usar dosis de 0,90 y $390 \mathrm{~kg} \mathrm{~N}^{-1} \mathrm{año}^{-1}$ parcializados en siete aplicaciones encontraron que el nivel de CHOS se reduce a medida que aumenta la fertilización, aunque a veces no encontraron diferencias significativas entre los tratamientos de 0 y $90 \mathrm{~kg} \mathrm{~N} \mathrm{ha}^{-1} \mathrm{año}^{-1}$.

El contenido de CHOS no mostró diferencias significativas entre las frecuencias de defoliación. Resultados similares obtuvieron Acharán et al. (2009) y Turner et al. (2006a). De la misma manera, Rawnsley et al. (2001) al evaluar la frecuencia de defoliación en pasto ovillo no encontraron diferencias en el nivel de CHOS al defoliar entre 1 y 4 hojas por macollo.

\section{Densidad de macollos}

La densidad de macollos aumentó a medida que se incrementó la fertilización nitrogenada. Los mismos resultados tuvieron Acosta et al. (1998) y Akmal y 
Janssens (2004), cuando compararon dos dosis de fertilización nitrogenada sobre L. perenne. Lestienne et al. (2006) también concuerdan que la fertilización nitrogenada aumenta significativamente la tasa de macollamiento. Onyeonagu y Asiegbu (2011), al usar dos tratamientos de fertilización nitrogenada en Panicum máximum Jacq. (0 y $300 \mathrm{~kg} \mathrm{~N} \mathrm{ha}^{-1}$ año $^{-1}$ ), encontraron que la fertilización aumentó la densidad de macollos, y al usar tres frecuencias de defoliación (4, 8 y 12 semanas) no encontraron diferencias sobre la tasa de macollamiento. Niklitschek (2011) también reportó aumentos en el número de macollos al aumentar la fertilización nitrogenada. Harris et al. (1996) reportaron un aumento de la densidad de macollos con el aumento de la dosis de fertilizante nitrogenado al usar 0,200 y $400 \mathrm{~kg} \mathrm{~N} \mathrm{ha}^{-1}$ año ${ }^{-1}$, obteniendo densidades de macollos fue de 4072, 6295 y 6673 macollos $\mathrm{m}^{2}$ respectivamente. Por lo tanto, el incremento en la fertilización aumentó el número de plantas $\mathrm{m}^{2}$.

McKenzie (1998) al usar dosis de $\mathrm{N}$ desde 120 hasta $720 \mathrm{~kg} \mathrm{~N} \mathrm{ha}^{-1} \mathrm{año}^{-1}$ obtuvo incrementos en la densidad de macollos desde 3500 hasta 17800 macollos m² respectivamente, aunque sobre $360 \mathrm{~kg} \mathrm{~N} \mathrm{ha}^{-1} \mathrm{año}^{-1}$ la respuesta fue muy baja. Esto se debe, de acuerdo a Fulkerson et al. (1993), a que la fertilización prolonga la supervivencia de los macollos y estimula la formación de nuevos macollos a partir de las yemas axilares. Por otra parte los componentes nitrogenados podrían asumir roles importantes en condiciones de bajos niveles de carbohidratos solubles para el rebrote (White, 1973).

La frecuencia de defoliación no tuvo efectos sobre la densidad de macollos de L. perenne, ni para otras gramíneas y tampoco para el total de gramíneas. A diferencia de este estudio, Niklitschek (2011) encontró un efecto significativo de la frecuencia de defoliación en el número de macollos. Turner et al. (2006b) y Turner et al. (2006a), en cambio, no encontraron diferencias en la tasa de macollamiento con distintas frecuencias de defoliación para L. perenne, Bromus willdenowii Kunth ni para D. glomerata. Donaghy y Fulkerson (2002) tampoco encontraron diferencias en la tasa de macollamiento con distintas frecuencias de defoliación, pero al igual que en este ensayo, observaron una disminución estacional con alta frecuencia de defoliación, como consecuencia de que entre enero y marzo son más los macollos senescentes que los macollos en formación. En este estudio la densidad de macollos de L. perenne no fue estadísticamente significativa, pero con tendencia a presentar un mayor número de macollos con la mayor frecuencia de defoliación. McKenzie (1997) al comparar tres frecuencias de defoliación (alta, media y baja) a comienzos de verano obtiene resultados significativos de mayor densidad de macollos con alta frecuencia de defoliación. Además, McKenzie (1997) encontró que la densidad de macollos disminuye a medida que avanza el verano, lo que concuerda con la disminución en el número de macollos visto en este ensayo, entre primavera y verano.

\section{CONCLUSIONES}

Los mayores niveles de fertilización nitrogenada aumentaron la producción de fitomasa y modifican la calidad nutritiva de la pradera, aumentando el contenido de PC y disminuyendo la fibra detergente neutro, fibra detergente ácida y los carbohidratos solubles, lo que fue más evidente con una mayor frecuencia de defoliación. La menor frecuencia de defoliación no aumentó la producción de fitomasa y se asoció a un aumento en la concentración de carbohidratos solubles y fibra detergente neutro, con una disminución del contenido de PC.

\section{REFERENCIAS}

Acharán, F., Balocchi, O., López, I., 2009. Filocrono, producción de fitomasa y calidad nutritiva de una pradera de Lolium perenne L./Trifolium repens $\mathrm{L}$. sometida a tres frecuencias e intensidades de defoliación. Agro Sur 37, 81-90.

Acosta, G., Cangiano, C., Miñon, D., 1998. Efectos del pastoreo y fertilización nitrogenada sobre el crecimiento y calidad de raigrás inglés (Lolium perenne). Investigación Agraria 13, 21-27.

Anwandter, V., López, I., Balocchi, O., 2008. Selectividad de vacas lecheras en pastoreo por cultivares de Lolium perenne L. Agro Sur 36, 15-26.

Akmal, M., Janssens, M.J.J., 2004. Productivity and light use efficiency of perennial ryegrass with contrasting water and nitrogen supplies Field Crops Research 88, 143155.

Auda, H., Blaser, R.E., Brown, R.H., 1966. Tillering and carbohydrate contents of orchardgrass as influenced by environmental factors. Crop Science 6, 139-43.

Balocchi, O., Pinochet, D., Wittwer, F., Contreras, P., Echeverria, R., Guzmán. F., 2001. Rendimiento y composición mineral del forraje de una pradera permanente fertilizada con magnesio. Pesquisa Agropecuaria Brazileira 36, 1309-1317.

Barker, D.J., Chu, A.C.P., Korte, C.J., 1985. Some effects of spring defoliation and drought on perennial ryegrass swards. Proceeding of the New Zealand Grassland Association 46, 57-63.

Beukes, P.C., Lee, J.M., Lancaster, J.A.S., Roche, J.R., 2006. Modelling the impact of changing the decision to graze from rotation length to ryegrass leaf-stage. Proceedings of the New Zealand Grassland Association 68, 275-281.

Bochi, O., Lopéz, S., García, R., Andrés, S., Calleja, A., 2009. Influence of harvest season, cutting frequency and nitrogen fertilization of mountain meadows on yield, floristic composition and protein content of herbage. Revista Brasileira de Zootecnia 38(4), 596-604.

Clark, D.A., Harris, S.L., 1996. White clover or nitrogen fertiliser for dairying? Agronomy Society of New Zealand Special Publication 11 / Grassland Research and Practice Series 6, 107-114. 
Clark, D.A., 2011. Changes in pastoral farming practices and pasture persistence - a review. Grassland Research and Practice Series 15, 7-14.

Correa, H.J., Cuellar, A.E., 2004. Aspectos clave del ciclo de la urea con relación al metabolismo energético y proteico en vacas lactantes. Revista Colombiana de Ciencia Pecuaria 17, 29-38.

Davies, A., 1971. Changes in growth rate and morphology of perennial ryegrass swards at high and low nitrogen levels. The Journal of Agricultural Science 77, 123-134.

Dirección Meteorológica de Chile, 2001. Climatología Regional. Departamento de Climatología, Santiago, Chile, pp. $1-45$.

Donaghy, D.J., Fulkerson, B., 1999. Principles for developing an effective grazing management system for ryegrassbased pastures. Dairy Research and Development Corporation, Tasmanian Institute of Agricultural Research (TIAR), Australia. pp. 1-10. https://www.researchgate. net/publication/268270994

Donaghy, D.J., Fulkerson, W.J., 2002. The impact of defoliation frequency and nitrogen fertilizer application in spring on summer survival of perennial ryegrass under grazing in subtropical Australia. Grass and Forage Science 57, 351-359.

Fulkerson, W.J., Slack, K., Moore, K., Rolfe, C., 1993. Management of Lolium perenne/Trifolium repens pasture in the subtropics. I. effect of defoliation interval, seeding rate and application of $\mathrm{N}$ and lime. Australian Journal of Agricultural Research 44, 1947-1958.

Fulkerson, W., Lowe, K., 2002. Forages and pastures. Grazing management, in: Roginski, H. (Ed.), Encyclopedia of Dairy Sciences. Academic Press, Australia, pp. 1142-1149. https://doi.org/10.1016/B0-12-2272358/00374-6

Gastal, F., Dawson, L.A., Thornton, B., 2010. Responses of plant traits of four grasses from contrasting habitats to defoliation and $\mathrm{N}$ supply. Nutrient cycling in agroecosystems 88, 245-258.

Grant, S.A., Barthram, G.T., Torvell, L., 1981. Components of regrowth in grazed and cut Lolium perenne swards. Grass and Forage Science 36, 155-168.

Harris, S.L., Thom, E.R., Clark, D.A., 1996. Effect of high rates of nitrogen fertiliser on perennial ryegrass growth and morphology in grazed dairy pasture in northern New Zealand. New Zealand Journal of Agricultural Research 39(1), 159-169.

Hoekstra, N.J., Struik, P.C., Lantinga, E.A., Schulte, R.P.O., 2007. Chemical composition of lamina and sheath of Lolium perenne as affected by herbage management. NJAS, Wageningen Journal of Life Sciences 55, 55-73.

Hopkins, A., Gilbey, C., Dibb, C., Bowling, P.J., Murray, P.J., 1990. Response of permanent and reseeded grassland to fertilizer nitrogen. 1. Herbage production and herbage quality. Grass and Forage Science 45, 43-55.

Instituto Nacional de Recursos Naturales-Universidad Austral de Chile (IREN-UACh), 1978. Estudio de Suelos de la Provincia de Valdivia. Santiago, Chile.

Keim, J.P., Anrique, A., 2011. Nutritional strategies to improve nitrogen use efficiency by grazing dairy cows. Chilean Journal of Agricultural Research 71, 623-633.

Lestienne, F., Thornton, B., Gastal, F., 2006. Impact of defo- liation intensity and frequency on $\mathrm{N}$ uptake and mobilization in Lolium perenne. Experimental Botany 57(4), 997-1006.

Loaiza, P.A., Balocchi, O., Bertrand, A., 2017. Carbohydrate and crude protein fractions in perennial ryegrass as affected by defoliation frequency and nitrogen application rate. Grass and Forage Science 72(3), 556-567.

López, I.F., Balocchi, O.A., Dörner, J., 2009. Evaluación de la frecuencia e intensidad de pastoreo sobre atributos productivos y de sustentabilidad en producción de leche. Informe segundo año. Universidad Austral de Chile. $21 \mathrm{p}$.

Márquez, F., Sánchez, J., Urbano, D., Dávila, C., 2007. Evaluación de la frecuencia de corte y tipos de fertilización sobre tres genotipos de pasto elefante (Pennisetum purpureum). 1. Rendimiento y contenido de proteína. Zootecnia Tropical 25(4), 253-259.

McKenzie, F.R., 1997. Influence of grazing frecuency and intensity on the density and persistence of Lolium perenne tillers under subtropical conditions. Tropical Grasslands 31, 219-226.

McKenzie, F. R., 1998. Influence of applied nitrogen on vegetative, reproductive, and aerial tiller densities in Lolium perenne L. during the establishment year. Australian Journal of Agricultural Research 49, 707-711.

Michell, P.J., Fulkerson W.J., 1987. Effect of grazing intensity in spring on pasture growth, composition and digestibility, and on milk production by dairy cows. Australian Journal of Experimental Agriculture 27, 35-40

Niklitschek, M.M., 2011. Efecto de dos frecuencias de defoliación y distintas dosis de nitrógeno sobre una pradera de ballica perenne (Lolium perenne L. cv Arrow) en la época de primavera-verano. Tesis Magister en Ciencias mención Producción Animal, Universidad Austral de Chile. 50 p.

Onyeonagu, C.C., Asiegbu, J.E., 2011. The effect of sward type, cutting frequency and fertilizer-N application on tiller production, yield and proportions of crop fractions of Panicum maximum with or without Stylosanthes hamata. African Journal of Biotechnology 10(74), 1683316848

Pacheco, D., Waghorn, G.C., 2008. Dietary nitrogen-definitios, degestion, excretion and consequences of excess for grazing ruminants. Proceedings of the New Zealand Grassland Association 70, 107-116.

Pedraza, C., Mansilla, A., Merucci, D., Pinedo, P., Contreras, H., 2006. Niveles de urea láctea en vacas de la región del Bío-Bío, Chile. Agricultura Técnica 66, 264-270.

Pembleton, K.G., Rawnsley, R.P., Turner, L.R., Corkrey, R., Donaghy, D.J., 2017. Quantifying the interactions between defoliation interval, defoliation intensity and nitrogen fertiliser application on the nutritive value of rainfed and irrigated perennial ryegrass. Crop and Pasture Science 68(12), 1100-1111.

Poff, J., Balocchi, O., López, I., 2011. Sward and tiller growth dynamics of Lolium perenne L. as affected by defoliation frequency during autumn. Crop and Pasture Science 62, 346-354.

Rawnsley, R.P., Donaghy, D.J., Fulkerson, W.J., Lane, P.A., 2001. Changes in the physiology and feed quality of cocksfoot (Dactylis glomerata L.) during regrowth. Grass and Fo- 
rage Science 57, 203-211.

Reyes, J., Vidal, I., Gonzalez, M., Fonte, D., 2000. Tres intensidades de pastoreo en el comportamiento del pasto estrella (Cynodon nlemfuensis). Revista Cubana de Ciencia Agrícola 34, 125-131.

Teuber, N., Elizalde, H., 1999. Efecto del corte en diferentes estados fenológicos de la ballica perenne en la evolución de una pradera de ballica con trébol blanco. Agro Sur 27, 94-104.

Turner, L.R., Donaghy, D.J., Lane, P.A., Rawnsley, R.P., $2006 a$. Effect of defoliation management, based on leaf stage, on perennial ryegrass (Lolium perenne L.), prairie grass (Bromus willdenowii Kunth.) and cocksfoot (Dactylis glomerata L.) under dryland conditions. 1. Regrowth, tillering and water-soluble carbohydrate concentration. Grass and Forage Science 61, 164-174.

Turner, L.R., Donaghy, D.J., Lane, P.A., Rawnsley, R.P., 2006b. Effect of defoliation management, based on leaf stage, on perennial ryegrass (Lolium perenne L.), prairie grass (Bromus willdenowii Kunth.) and cocksfoot (Dactylis glomerata L.) under dryland conditions. 2. Nutritive value. Grass and Forage Science 61, 175-181.

Van Loo, E.N., 1992. Tillering, leaf expansion and growth of plants of two cultivars ryegrass grown using hydropo- nics at two water potentials. Annals of Botany $70(6)$, 511-518.

Velasco, M.E., Hernández, A., Gonzáles, V.A., 2007. Cambios en los componentes del rendimiento de una pradera de ballica perenne, en respuesta a la frecuencia de corte. Revista Fitotecnia Mexicana 30(1), 79-87.

Waite, R., Johnston, M.G., Armstrong, D.G., 1964. The evaluation of artificially dried grass as a source of energy for sheep 1 . The effect of stage of maturity on the apparent digestibility of ryegrass, cocksfoot and timothy. Agricultural Science 62, 391-398.

White, L.M., 1973. Carbohydrate Reserves of grasses: A review. Journal of Range Management 26, 13-18.

Whitehead, D.C., 1995. Grassland Nitrogen. CABI International, Wallingford, UK.

Wilman, D., Pearse, P., 1984. Effects of applied nitrogen on grass yield nitrogen content, tillers and leaves in field swards. The Journal of Agricultural Science 103, 201211.

Wittwer, F., Opitz, H., Reyes, J.M., Contreras, P.A., Böhmwald, H., 1993. Determinación de urea en muestras de leche en rebaños bovinos para el diagnóstico de desbalance nutricional. Archivos de Medicina Veterinaria 25, 165172. 
